\title{
Physicians for Africa: rewriting the way in which postgraduate medical education is delivered and assessed in east, central and southern Africa
}

\author{
Authors: Liam Fisher-Jones, ${ }^{\mathrm{A}}$ Evarist Njelesani ${ }^{\mathrm{B}}$ and Iain Fossey ${ }^{\mathrm{C}}$
}

\begin{abstract}
Aims
Africa has $25 \%$ of the world's disease burden but only $1.5 \%$ of the world's doctors. The newly established East, Central and Southern Africa College of Physicians (ECSACOP) is rewriting the way in which postgraduate medical education is delivered and assessed in the region, while aiming to double the output of physicians being trained by 2030 .

\section{Methods}

The first step: to ensure those enlisted to teach at ECSACOP training centres have excellent, current skills in transferring knowledge to adults through the delivery of a series of 'Doctors as educators' courses. Through 2017, ECSACoP started assembling and training a cohort of senior physicians from across the region. This group of African medical leaders - the faculty - is learning and training together, familiarising itself with the newly developed ECSACoP training curriculum, while adopting the same regional training methodologies; an essential step before training can begin at the identified sites. Senior physicians first assembled in Lusaka, Zambia in May 2017 to undertake an intensive 3-day educational leaders course. This first course was followed by a second course in Entebbe, Uganda from 1-3 October 2017. The courses combined interactive participatory sessions with workstreams that were tasked with both performing practical tasks and determining future college policy. Mentoring groups were established to allow time for in-depth reflection and discussion.
\end{abstract}

\section{Results}

As evidenced through detailed post-course questionnaires.

$>40$ medical leaders have a refreshed and reinvigorated sense of what being an educator entails.

> These medical leaders have improved self-awareness around educational capabilities and competencies.

Authors: ${ }^{A}$ East, Central and Southern Africa College of Physicians, Kampala, Uganda; ${ }^{B}$ President, East, Central and Southern Africa College of Physicians, Lusaka, Zambia; ${ }^{C}$ Royal College of Physicians, London, UK
> A community of practice has been established - a coherent faculty, networked and collegiate.

> Shared values and ambitions for the future of ECSACoP have been embedded within the group.

\section{Conclusion}

To date, this faculty development programme has equipped ECSACOP trainers with an understanding of ECSACOP's new curriculum and how best to deliver it. Training is due to commence at accredited training centres during 2018.

An additional benefit of the programme was that participants were able to feedback on key strategic documents, bringing a range of national perspectives to discussions about the college's governance. ECSACoP's syllabus and curriculum have been refined and a training centre accreditation toolkit developed.

\section{Conflict of interest statement}

None. The Royal College of Physicians is supporting ECSACoP's Council during this formative period by providing mentorship, technical support and access to a range of external experts to advise on specific challenges faced. 